\title{
Evaluation of Sustainable Practices within Project Management Methods
}

\author{
Satya Shah ${ }^{1,}$, Elmira Naghi Ganji ${ }^{1}$ and Alec Coutroubis ${ }^{1}$ \\ ${ }^{1}$ Applied Engineering and Management, Faculty of Engineering and Science, University of Greenwich, UK
}

\begin{abstract}
The purpose of this research study is to investigate some of the sustainable practices within projects with a focus on social projects. The different research methodologies applied through this research consisted both primary and secondary research, including literature review and through case study. The stakeholder's behavioural needs towards acting and implementing sustainable practices led to the adoption of sustainable practices within projects which are managed across profit and non-profit organisations. Nevertheless, lack of sustainable behaviour was outlined, and henceforth the integration of sustainable development within social projects is crucially important as such projects were identified as the drivers toward educating the society in order to help to produce generations of people who would be more sustainably aware. Currently, sustainable development is very often taken into account when it comes to managing projects. Nevertheless, if the adoption of sustainable practices is well established in some sectors such as construction, literature tends to demonstrate a lack of information regarding other sectors, especially within social projects. This research aims to investigate the adoption of sustainable practices within social projects and therefore to satisfy a literature gap.
\end{abstract}

\section{Introduction}

The earth is facing major environmental issues mostly due to the current practices used within a world of consumption and globalization. In the last two decades, the concept of sustainability and accountability has become an emerging characteristic of the enterprises worldwide. Improving significant aspects of a company success such as economic, social and environmental performance; sustainability defines a strategy to transform businesses towards long-term prosperity. The awareness of the population is constantly increasing and a real need of change now appears as vital in order to preserve the environment but also to stimulate ethical behaviours [1]. The triple bottom line of sustainable development aims to respond to the present needs in focusing on three major aspects: the environmental, economic and social aspects [2]. Presently, most of the governments promote the positive effects of an on-going transition to a potential green economy. Nevertheless, even if the environmental sector is growing very fast, this is a long process that requires major changes at different levels. This means that several gaps have not been explored yet and there is still a considerable need of more research and improvements.

Project Management is a discipline that can be applied in every business, organisations and governments or even in everyone's private life. Adopting a new way of tackling projects integrating the concept of sustainability will impact on most of people's personal or professional habits. The benefit of the implementation of sustainability within building approaches has already been undeniably well established [3]. Literature tends to demonstrate a lack of information regarding other sectors, especially within social projects. Therefore, this research aims to examine the possible gaps within the integration of sustainable development within social projects and expects to provide recommendations in order to contribute to the success of sustainability.

Furthermore, the world literature would provide suitable secondary resources related to the application of sustainable practices within the for-profits and non-profits organisations and also makes a bridge between the two mentioned organisations, as a more reliable term called "hybrid organisation" [4]. Finally, based on a clear roadmap and its five different pillars, this study seeks to examine the concept of environmental sustainability and social awareness through the conduction of a survey questionnaire of Company $\mathrm{AB}$. Hence, the research primary resources will be provided. According to the analysis and final results; a set of ultimate statements and recommendations for future research will be presented based on the limitations of this research.

\section{Literature Review}

The review of literature seeks to outline the conceptual framework of the research by presenting a review of advantages, disadvantages, motivations, drivers and hurdles towards the use of sustainable practices within project management methods, especially with the key focus towards social projects in particular. The key

$\overline{{ }^{a} \text { Corresponding author: s.shah@gre.ac.uk }}$ 
research areas of this study aims to focus towards the following areas as highlighted in Figure 1.

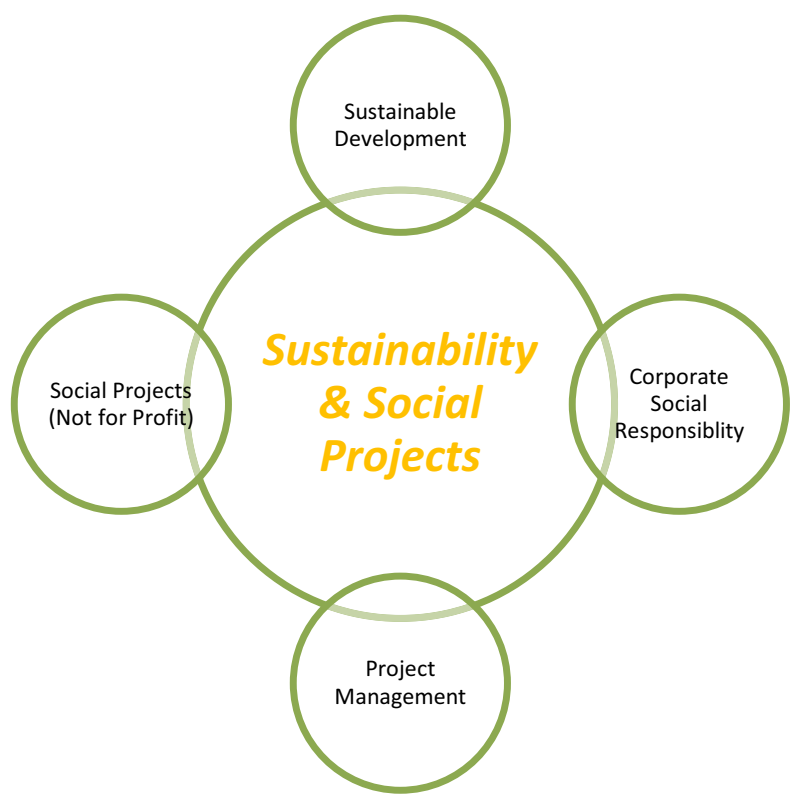

Fig. 1. Research Focus of Sustainability and Social Projects

\subsection{Sustainable Development}

The meaning of sustainable development was defined by The World Commission on Environment and Development [5] as "development that meets the needs of the present without compromising the ability of future generations to meet their own needs". This study aims to investigate some of the sustainable practices adopted within projects with a focus on social projects. Therefore, sustainable development is considered as the major component of this research. This is why an understanding of the concept and the relevance of sustainable development is necessary in order to successfully fulfil the focus of this research.

Recent literature has identified that the issue of sustainability has increasingly influenced the business world for the past 30 years. The concept of sustainable development has been widely associated with three components called the triple bottom line: economic activity, social progress and environmental responsibility. In addition, the research asserts that a balanced approach to these three aspects and a sensible use of the planet's resources is the only way to lead to a sustainable future [2]. In order to achieve this balanced approach, numerous different practices exist. The notion of "practices" was defined by [6] as "the elements like shared routines or behaviour, models, guidelines and policies"; they may exist at different levels. Sustainable practices can be associated with the main aspects of sustainable development such as pollution, waste and recycling, climate change, corporate social responsibility, cultural dimensions, global awareness or globalisation, as examples. This study aims to identify current sustainable practices adopted within projects. However, at the start of this research study, the author's only aims to address the two important key areas of corporate social responsibility (CSR) and community awareness.

\subsection{Corporate Social Responsibility (CSR)}

Recent literature tends to outline that the concept of CSR is debated and argued to be unclear and hard to define. [7]. However, as it is also a growing notion, different authors have tried to define it. Other research studies explains Corporate Social Responsibility as a concept integrating a wide range of issues involved in the relationship between an organisation's actions and those affected by them [8]. Therefore, achieving corporate social responsibility is about meeting the needs of the stakeholders [9]. This author also clarifies the concept by expressing the following range of issues which should be covered through dealing with CSR: the employee relations, human rights, corporate ethics, community relations and the environment. Recent literature has also identified the concept of Corporate Social Responsibility as a main contribution to sustainable development as it encourages organisations to act socially responsibly and therefore integrate at least one of the three dimensions of the triple bottom line of sustainable development [10].

However, most of the organisations are starting to see the economic potential of the integration of sustainable development. This is why it is also important to highlight that adding economic value to corporate social actions can be considered as reducing the moral validity. In fact, [11] argues that trying to achieve superior profit through social initiatives perverts the essence of CSR. These findings provides the researchers to have a better understanding of the concept of corporate social responsibility which is one of the key areas of sustainable development this research focusses upon. Research studies define environmental awareness as the individuals' vigilance in noticing environmental problems and beliefs about their potential adverse consequences [12]. Research explains that among its principles, sustainable development encourages the mobilization of individuals, including women, youth and various communities to take an active role in achieving sustainable development [13]. Recent literature has mainly demonstrated a significant and increasing awareness of global environmental problems as well as a need of improvements to ensure the protection of the environment [1].

\subsection{Project Management}

Literature explains that traditionally, the management of projects is now considered as a science due to the growing number of Project Management institutions and associations. It is the discipline of managing projects successfully [14]. The research does not aim to define project management but to link it to the concept of sustainable development, mainly focusing on the two key areas mentioned previously as CSR and community awareness. Hence, the authors intend to provide the main focus on evaluating the integration of sustainable practices within projects. As discussed earlier, research studies have shown an increasing environmental awareness from the community. This is why stakeholders demand is probably one of the factors that drove the project management industry to integrate sustainability. Literature showed that government and multinational corporations are the two 
main customer groups currently requesting sustainability within projects [15]. In addition, it asserts that this demand will increase, which again states the importance of the integration of sustainable principles within project management. This led to the birth of a new concept termed as "green project management".

According to research studies by [16], Green Project Management is still considered in its infancy. In fact, the idea of applying green standards within projects is quite new. Green Project Management aims to incorporate environmental aspects into project management processes. It is about thinking green throughout the whole project and making decisions in order to reduce the possible impact on the environment with the intention of preserving it. The literature insists that the point is not to make every decision about the environment and to evaluate if it is eco-friendly enough or not; the purpose is to take into account potential environmental impacts instead of ignoring them [16].

One of the research objectives is to analyse the impact of the use of sustainable methods on the project stakeholders. Throughout research it suggests that project stakeholders are closely linked to both the concept of sustainable development and of project management. In fact, this study has identified that stakeholder management is increasing considerably in the context of sustainable development. It has also stated that in order for projects to meet stakeholders' needs and expectations, project management will have to be done in the context of sustainable development. So far, it appears that project stakeholders could be engaged with sustainable development in two slightly different ways. The first one is of course, the increasing demand of stakeholders for achieving sustainability. The second is the promotion of sustainability through the stakeholders' engagement.

\subsection{For-Profit and Non-Profit Organisations}

According to a study, non-profit organisation refers to "an entity that legally prohibited from disturbing profits to its shareholders or managers" [17]. These organisations operate within various fields such as charity, clothing and shelter, labour, sports, health and safety, food delivery, politics, religion, defence, altruism, liberty, business support and civil rights [18]. As it is evident from the statistics, 1,478,194 non-profit organisations existed in the US in 2006 which was $36 \%$ more than its last decade [19]. Besides, there is a tight competitiveness among these organisations, as some of the researchers have utilised the porter's five forces in order to monitor the competitor's intensity in those environments [20]. The mentioned factors act as major motivations for these organisations to move towards sustainability, especially considering their most important missions for social and moral missions.

The study aims to focus towards social sustainability and its adoption within the projects of an organisation. In addition, it intends to compare the use of the sustainable practice within profit and non-profit organisations. Hence, the research investigates the profit and non-profit organisations and the adoption of sustainability practices within these environments. A recent study investigates 10 different cases of social non-profit organisations in Australia and explores their need to develop sustainable practices both in strategic and operational levels of management in order to obtain strategies to measure social entrepreneurship theory [21]. They interviewed the CEOs and senior managers of the companies and achieved 3 propositions according to the results of their questionnaire based approach. Firstly, the environmental changes such as climate change push the businesses to adopt sustainable approaches. Secondly, achieving financial benefits leads them to adopt operational decisions and proper strategies which are compatible with sustainability. Thirdly, the need to balance the three pillars of sustainability and to adopt multiple innovation strategies persuade them towards organisational sustainability [21].

Regarding the for-profit organisations, a research paper examines the influence of stakeholder's pressures towards environmental sustainability of an adhesive manufacturing industry through a qualitative survey [22]. As reported, again competitive advantage plays a vital role in this case as a critical motivator. Profitability, business image, availability of quality management standard, minimizing environmental impacts, government regulations, customer demand and staff awareness enhancement are the parameters that are very important towards the adoption of environmental sustainability. Furthermore, high industry competition and shareholders' inspiration exert the most important influential factors for environmental management system (EMS) adoption. The shareholder's desire is due to the fact that the factors such as financial performance, energy and water consumption and recycling are their major business challenges, and hence, move them towards adoption of sustainable practices [22].

A research paper utilises the term "hybrid organisation" to make a linkage between the non-profit and for-profit organisations in order to create an effective way moving towards social and environmental changes [23], whereas, hybrid organisation also known as fourth sector, L3C, Blended value, benefit corporation and mission driven, refers to "the start-up that combines different institutional logics in unprecedented ways" [24]. In other words, the hybrid organisation mixes the parameters, value systems and action logics such as social responsibility and financial profits from different society sectors such as public sector and non-profit sector. Explaining the way that hybrid organisations contribute to the environmental protection and social impacts, a theoretical model called Sustainability-driven Business Model is defined [23]. The main factors of this model includes social change as organisational objective, effective relationship between the stakeholders and consistent interaction with markets, competitors and industry institutions. This model identifies the key distinctive factors between the traditional and hybrid organisations. In terms of corporate social responsibility (CSR) and environmental issues, the traditional ones only address these issues if they access to sufficient resources, strong business plans and gain enough profits; whereas hybrids integrate their business cases with explicit environmental objectives. In terms of stakeholder's relationship, the traditional ones rely on financial profit as a critical factor, however, hybrids firstly consider mutual benefits and sustainability results. 


\section{Research Methodology}

This research is based on both qualitative and quantitative data which is facilitated through detailed company survey using site visits, themed interviews and questionnaire administration. Furthermore, reviewing the history and background of the company, all the publicity available materials such as company website and brochures were used within the research.

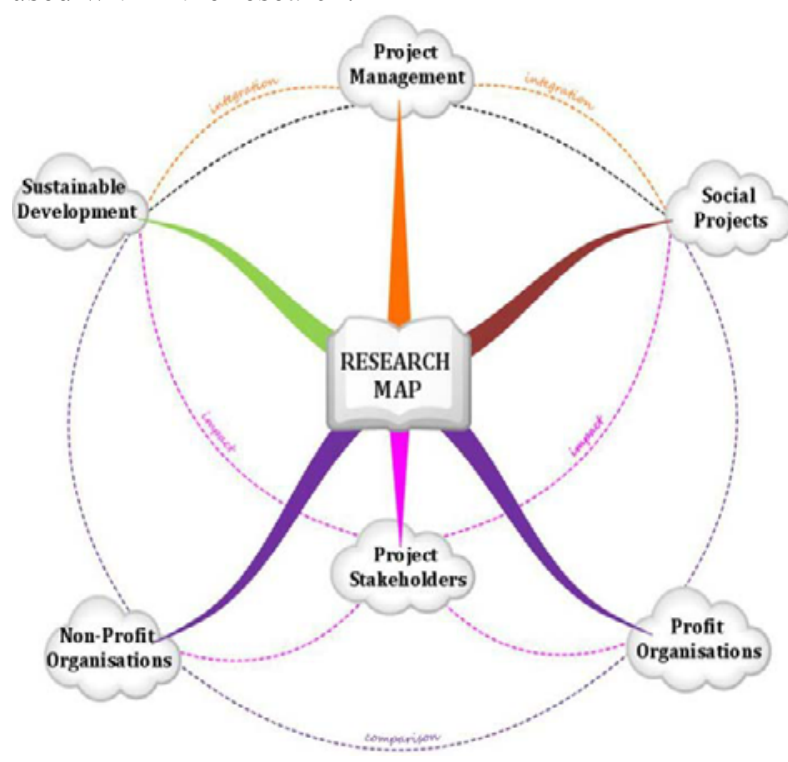

Fig. 2. Research Roadmap.

The objectives of the research which aims to satisfy by conducting primary research are as follows:

a) To understand project stakeholders' behavioural needs towards acting and implementing sustainable practices.

b) To compare the use of the identified sustainable practices and its adoption within profit and nonprofit organisations.

c) To identify the importance and relevance of sustainable development within social projects.

The proposed research seeks to describe the characteristics on adoption of sustainable practices and especially within profit and non-profit based organisations. The research aims to evaluate the findings based on the collected data from document research, industry association data from the interviews and also any government environmental or sustainability regulations, therefore it would be a descriptive research. The population of the study is the personnel of Company $\mathrm{AB}$ consisting of the shareholders and senior managers due to their primary knowledge; current, accurate and factual data they can present for the research purpose. As a result, the researcher will be able to draw assumptions and derive findings based on the existing information and perform the analysis in the higher steps. In Company AB, seven main parties were involved in meetings and helped the authors to write up the observations and findings. The key questions identified for the qualitative data collection is as shown below in table 1 out of the given eighteen questions within the survey. The research also aims to focus on using expert interviews to develop further understanding of how the organisations behaves towards the concept of sustainable development (SD); and integrating SD while undertaking projects.

Table 1. Key Research Survey Questions.

\begin{tabular}{|c|c|c|}
\hline No. & Question & Description \\
\hline 5 & $\begin{array}{l}\text { Are you familiar } \\
\text { with the concept of } \\
\text { sustainable } \\
\text { development }\end{array}$ & $\begin{array}{l}\text { To investigate if the } \\
\text { respondents (as potential } \\
\text { project stakeholders) are } \\
\text { aware with the concept of } \\
\text { sustainable develop. }\end{array}$ \\
\hline 7 & $\begin{array}{l}\text { How aware are you } \\
\text { of environmental } \\
\text { issues? }\end{array}$ & $\begin{array}{l}\text { To investigate if the } \\
\text { respondents are aware of } \\
\text { environmental issues. }\end{array}$ \\
\hline 8 & $\begin{array}{l}\text { I consider } \\
\text { environmental } \\
\text { issues as a priority } \\
\text { in today's world. }\end{array}$ & $\begin{array}{l}\text { To investigate what extend the } \\
\text { respondents agree with } \\
\text { statements in order to } \\
\text { understand if they consider } \\
\text { environmental issues as a } \\
\text { priority in today's world and } \\
\text { if they feel like their actions as } \\
\text { an individual impact on the } \\
\text { environment. }\end{array}$ \\
\hline 13 & $\begin{array}{l}\text { I refuse to deal with } \\
\text { an organisation that } \\
\text { does not consider } \\
\text { sustainable } \\
\text { development. }\end{array}$ & $\begin{array}{l}\text { To investigate what extend the } \\
\text { respondent agree with } \\
\text { statement in order to } \\
\text { understand if they would } \\
\text { refuse-or not- to deal with an } \\
\text { organisation doesn't consider } \\
\text { sustainable development. }\end{array}$ \\
\hline 11 & $\begin{array}{l}\text { Rank the following } \\
\text { five characteristics } \\
\text { in order of imp. For } \\
\text { you when buying a } \\
\text { product. }\end{array}$ & $\begin{array}{l}\text { To investigate what are the } \\
\text { priorities of the respondents } \\
\text { when buying a product. }\end{array}$ \\
\hline 14 & $\begin{array}{l}\text { Some Orgs. Are } \\
\text { promoting their } \\
\text { involvement in } \\
\text { Sust. Develop. How } \\
\text { does this impact on } \\
\text { your behaviour? }\end{array}$ & $\begin{array}{l}\text { To understand the impact of } \\
\text { promotion of Orgs. } \\
\text { Involvement in sust. } \\
\text { development on the } \\
\text { respondents (potential } \\
\text { stakeholders) }\end{array}$ \\
\hline 15 & $\begin{array}{l}\text { As a stakeholder, } \\
\text { do projects } \\
\text { integrating Sust. } \\
\text { Develop. Increase } \\
\text { your Env. } \\
\text { Awareness? }\end{array}$ & $\begin{array}{l}\text { To investigate if projects } \\
\text { integrating Sust. Develop. } \\
\text { Increase the respondent's Env. } \\
\text { Awareness. }\end{array}$ \\
\hline 9 & $\begin{array}{l}\text { Have you heard } \\
\text { about "CSR"? }\end{array}$ & $\begin{array}{l}\text { To investigate the } \\
\text { understanding of CSR }\end{array}$ \\
\hline 16 & $\begin{array}{l}\text { Rank the following } \\
\text { four sustainable } \\
\text { practices in order of } \\
\text { importance for you } \\
\text { when taking part of } \\
\text { a project. }\end{array}$ & $\begin{array}{l}\text { To investigate what are the } \\
\text { most important sustainable } \\
\text { practices for the project } \\
\text { stakeholders. }\end{array}$ \\
\hline 17 & $\begin{array}{l}\text { How do you } \\
\text { consider the } \\
\text { integration of SD } \\
\text { within social } \\
\text { projects compared } \\
\text { to other projects? } \\
\end{array}$ & $\begin{array}{l}\text { This question aims to gain the } \\
\text { respondents' opinions on the } \\
\text { relevance of SD within social } \\
\text { projects. }\end{array}$ \\
\hline & & \\
\hline
\end{tabular}




\section{Results and Discussions}

As mentioned earlier within the paper the research focuses on the use of survey analysis methods to get a better understanding towards stakeholders' behavioural needs. In order for the results to be as representative as possible and therefore exploitable, the survey panel had been diverse.

\subsection{Awareness and Knowledge of Sustainable Development}

The question has been identified as key question in order to identify the awareness and knowledge of the participants towards sustainable development. The graph below in Figure 3 represents the percentages obtained for this question. As it can be identified in the graph, $90 \%$ of the respondents are familiar with the concept of sustainable development against only a small $10 \%$ who suggest they are not aware of it. This percentage is significant and demonstrates the increasing awareness of people towards the concept of sustainable development. Sustainable development is associated with three components: the economic, social and environmental aspects [2].

\section{Are you familiar with the concept of sustainable development?}

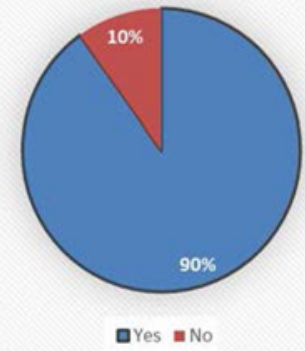

Fig. 3. Analysis towards Familiarity of Sustainable Development Concept.

\subsection{Stakeholder's Behaviour towards Sustainable Development}

Following the findings of the analysis of questions 5, 6 and 7 , it was decided to investigate if the increasing awareness and knowledge of sustainable development had any kind of impact on the stakeholders' behaviour. In order to do so, the results of question 8 are going to be compared with questions 11 and 13.

\section{I consider environmental issues as a priority in today's world.}

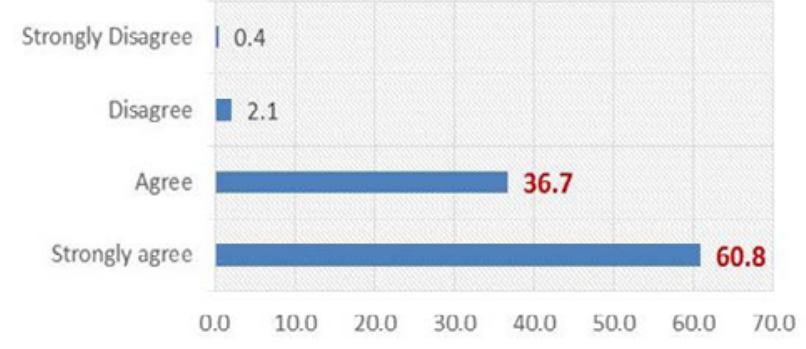

Fig. 4. Consideration of Environmental Issues.
The analysis of question 8 demonstrates that a significant number of the respondents consider environmental issues as a high priority. Indeed, as outlined in Figure 10, 60.8\% of them strongly agree with the statement together with another $36.7 \%$ also agreeing to it. This, once again, confirms the result of question 7 and validates the increasing environmental awareness within the society with $97.5 \%$ of the stakeholders considering environmental issues as a priority in today's world. However, further analysis shows that this is not always very well reflected within their behaviour. Indeed, the consideration of questions 11 and 13 shows those stakeholders do not always act towards sustainability.

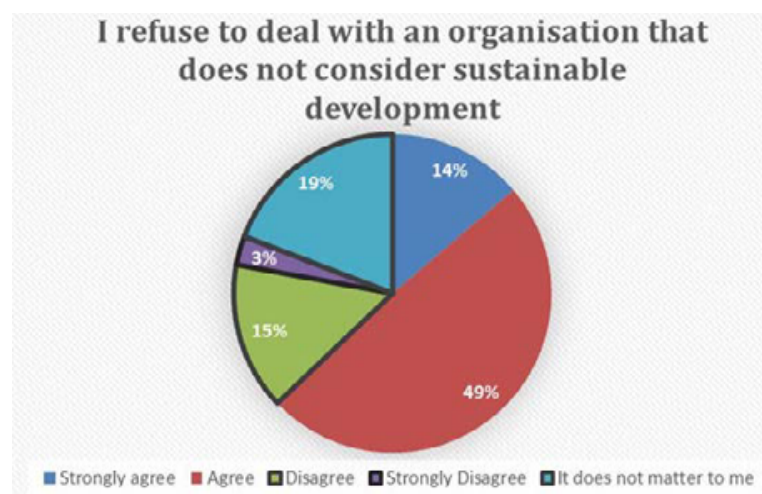

Fig. 5. Adoption of Behaviour towards Environmental Concerns.

Question 13 sought to investigate to what extent the respondents were likely to adopt a behaviour responding to their environmental concern. Reflecting on the results of question 8 , it was expected that only $2.5 \%$ of the respondents would not feel the need to deal with an organisation that does not consider sustainable development. Nevertheless, it was demonstrated that $18 \%$ of the respondents would easily deal with an organisation that does not consider sustainable development. In addition to this, $19 \%$ of them suggest that this does not matter to them.

\subsection{Interactions with Organisations Promoting Sustainable Development}

The comparison of question 7 with questions 13 and 11 demonstrated that the awareness of the stakeholders towards sustainable development is not always reflected through their adopted behaviour. Nevertheless, further analyses seem to demonstrate a way of mobilising their sustainable behaviour. In order to do so, it was chosen to compare questions 12 and 14. Question 14 asked the respondents how likely they were to make themselves aware of an organisation's responsibility towards sustainability. As a result, $18 \%$ of the respondents would be very likely to do so. $26 \%$ of the panel would be unlikely to or would not make them aware of an organisation's responsibility towards sustainable development. Keeping these results in mind, the author then compared them with the results of question 14 . 
Some organisations are promoting their involvement in sustainable development.

How does this impact on your behaviour?

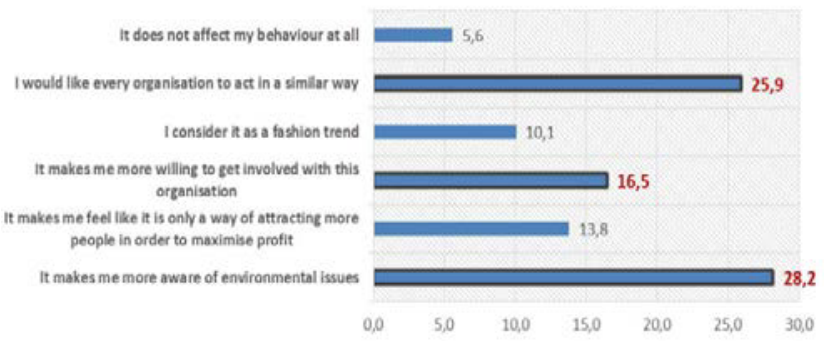

Fig. 6. Aware of Organisation's Responsibility towards Sustainability.

Indeed, question 14 sought to understand the impact of an organisation's promotion of sustainable development on the stakeholders' behaviour. As shown in Figure (6) these are the three main responses chosen by the panel:

- $28.2 \%$ of the respondents feel more aware of environmental issues;

- $25.9 \%$ of the respondents would like every organisation to act in a similar way;

- $16.5 \%$ of them would be more willing to get involved within this particular organisation.

Project stakeholders might not be willing to make them aware of an organisation's responsibility towards sustainable development; yet it is demonstrated that its promotion from the organisation itself will impact positively on the stakeholders' behaviour. Therefore, the comparison of the two questions resulted in the following conclusion: the organisations' promotion of their involvement in sustainable development can be a way of mobilising sustainable behaviour.

\subsection{Sustainable Development and Project Management}

The second part of the survey intended to gain further knowledge towards the integration of sustainable development within project management. The participants were asked their opinions on the integration of sustainable development within projects together with their understandings of Corporate Social Responsibility.

\section{As a stakeholder, do projects integrating sustainable development increase your environmental awareness?}

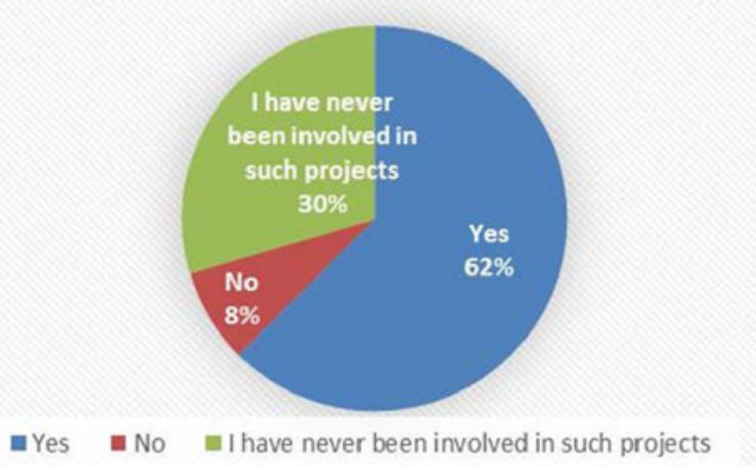

Fig. 7. Projects Integrating SD on Environmental Awareness.
Question 15 sought to investigate if projects integrating sustainable development increased the respondent's environmental awareness. As outlined in Figure 7, the majority of the respondents believe that sustainable projects increase their environmental awareness. Indeed, $89 \%$ of the respondents who were involved in such a project believe so. Therefore, this highlights the relevance of the adoption of sustainable practices within projects. Nevertheless, this question also demonstrates that $30 \%$ of the respondents have never been involved in such projects. This percentage shows that this adoption is not always well-established within projects; there is still a considerable room for improvement. First, the respondents who had already participated in a social project were questioned about the integration of sustainable development within their own. The analysis of question 20 outlines that only $39 \%$ of the social projects in which the respondents participated in integrate sustainable development (Figure 8).

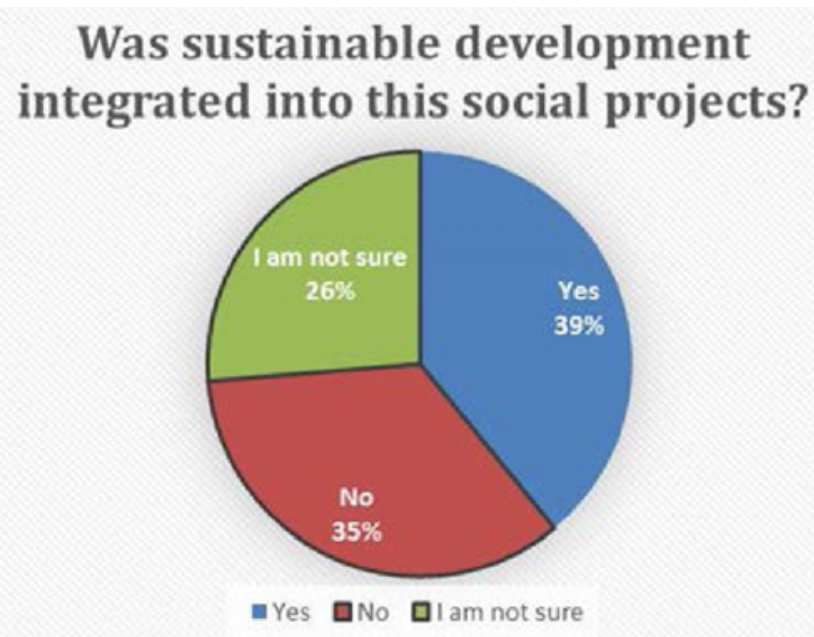

Fig. 8. Sustainable Development in Social Projects.

In addition to this, $26 \%$ of the panel are not sure whether sustainable development was integrated or not within the projects they participated in. This might demonstrate a lack of communication towards sustainability with the project stakeholders; this could also again highlight the fact that people can be aware of sustainable development but not always knowledgeable enough to recognise sustainable practices. Overall, the analysis shows that the integration of sustainable development is not wellestablished within social projects.

Question 17 consisted in getting the respondents' opinion regarding the importance of the integration of sustainable development within social projects. The majority of the panel (66.3\%) suggested that such integration was equally important compared to other types of projects. And yet, $18.3 \%$ of the respondents believe that such integration is more important within social projects than others. The analysis of question 17 demonstrates that the panel essentially believes that sustainable development should equally been integrated within any types of projects. Nevertheless, the analysis also enabled to gather the opinion of respondents thinking that the integration of sustainable development is even more important within social projects due to their nature. 


\section{Conclusions}

The research addresses the importance and use of sustainable practices adopted within projects, with a focus towards social projects. To achieve the aim of the study, the research derived some key research objectives. Firstly, the research focusses on identifying current sustainable practices within projects, focusing on Corporate Social Responsibility (CSR) and Community Awareness. The research also aimed to understand project stakeholders' behavioural needs towards acting and implementing sustainable practices; and to compare the use of the identified sustainable practices and its adoption within profit and non-profit organisations. Preliminary research was first outlined through literature studies, highlighting the increase environmental awareness of project stakeholders. However, lack of understanding of how their behaviour influence sustainable practices were still remaining. Further studies carried out identified the gap through analysing and discussing the results of the survey. Results highlighted that there was significant increase of environmental awareness and demand towards sustainability from the project stakeholders, including lack of sustainable behaviour; and possibility of mobilising sustainable behaviour through the organisations' promotion of their involvement in sustainable development. The study provided a brief understanding through the literature, identifying the necessity for organisations to deal with sustainability in order to maintain their project stakeholders. Nevertheless, the comparison of the adoption of sustainable practices within projects was not clearly identified through secondary research. It was understood within the literature review that no recent research had been established towards the integration of sustainable development within social projects. Therefore, further analysis of the data presented that there was a lack of integration of sustainable practices within social projects. The integration of sustainable development within social projects was identified as crucially important and relevant: social projects are the drivers towards educating the society regarding sustainable development.

It is discovered that the non-profits' core objectives and activities are more correspondent to the sustainable practices. Therefore in order to develop the social responsibility within the world businesses, the for-profit business managers require adopting managerial strategies and organisational cultures to change the neutrality of staff mind-sets regarding the sustainable practices to lead the businesses towards prosperity going greener. Further research studies towards better understanding of the economic dimension of sustainable development, rather than just the environmental and social aspects of sustainable development within projects is planned. And finally, other type of sustainable practices than CSR and community awareness such as climate change, pollution and waste management practices and effects of globalisation could be investigated in future research studies.

\section{References}

[1] M. Chavan, An appraisal of environment management systems, I.J. of MEQ, 16 (5), 444-463 (2005)

[2] M. Koukiasa, Sustainable facilities management within event venues. Worldwide Hospitality and Tourism Themes, 3 (3), 217-228 (2011)

[3] C.A. Hodges, Facility manager's approach to sustainability. Journal of Facilities Management, 3 (4), 312-324 (2005)

[4] N. Haigh, A. J. Hoffman, Hybrid organisations: The next chapter of sustainable business. Organizational Dynamics. 41, 126-134 (2012)

[5] World Commission on Environment and Development (WCED). Our Common Future, Oxford University Press, Oxford (1987)

[6] R. Whittington, Completing the practice turn in strategy research, Organization Studies, 27 (5), 613-34 (2006)

[7] T. Mysen, Sustainability as corporate mission and strategy. European Business Review, 24 (6), 496-509 (2012)

[8] A. Murra, K. Haynes, LJ. Hudson, Collaborating to achieve corporate social responsibility and sustainability Possibilities and problems. Sustainability Accounting, Management and Policy Journal, 1(2), 161-177 (2010)

[9] L. Moir, What do we mean by corporate social responsibility, Corporate governance, 1 (2), 16-22 (2001)

[10] J. Moon, The Contribution of Corporate Social Responsibility to Sustainable Development. Sustainable Development, 15, 296-306.

[11] T. Ketola, A holistic corporate responsibility model: integrating values, discourses and actions, Journal of Business Ethics, 80, 419-35 (2007)

[12] B.M. Wiernik, D.S. Ones, S. Dilchert, Age and environmental sustainability: a meta-analysis. Journal of Managerial Psychology, 28 (7/8), 826-856 (2013)

[13] L. Swanson., D. Zhang, Perspectives on corporate responsibility and sustainable development. Management of Environmental Quality: An International Journal, 23 (6), 630-639 (2012)

[14] A.A.E. Othman, N. Sirbadhoo, An innovative partnership framework for sustainable development of rural areas in South Africa: Journal of Engineering, Design and Technology, 7 (3), pp. 243-263 (2009)

[15] F. Pelham, Will sustainability change the business model of the event industry? WHATT, 3 (3), pp. 187-192 (2011)

[16] M. Labrosse, Incorporating Green in Project Management. Employment Relations Today, 37 (3), 85-90 (2010)

[17] H. B. Hansmann, The role of non-profit enterprise. Yale Law Journal, 89 (5), 835-901 (1980)

[18] National Centre for Charitable Statistics at the Urban Institute. (2009a). Number of non-profit organizations in the United States, 1996-2006.

[19] National Centre for Charitable Statistics at the Urban Institute. (2009b). Number of non-profit organizations in the United States, 1996-2006.

[20] J. B. Ritchie, C.B Weinberg, A typology of non-profit competition: Insights for social marketers. Social Marketing Quarterly, 6 (3), 64-71 (2000)

[21] J. Weerawardena, R.E. McDonald, GS. Mort, Sustainability of non profit organisations: An empirical investigation. Journal of World Business. 45, 346-356 (2010)

[22] S. Shah, E. Ganji, S. Hasan, Environmental management Systems and sustainability in SMEs, MATEC, 76, (2016)

[23] N. Haigh, A. J. Hoffman, Hybrid organisations: The next chapter of sustainable business. Organizational Dynamics. 41, 126-134 (2012)

[24] J. Battilana, S. Dorado, Building sustainable hybrid organisations: The case of commercial Microfinance organisations. AMJ. 53 (6), 1419-40 (2010) 